\title{
Rethinking of Instructional Short Movies and Videos: An Evaluation the Instructional Short Movie and Video Competition*
}

\author{
Oktay AKBAŞ ${ }^{* *}$
}

\author{
Serap Nur CANOĞLU $\mathbf{U}^{* * *}$
}

\author{
Mustafa CEYLAN ${ }^{* * * *}$
}

Received: 31 January 2014

Accepted: 01 March 2015

\begin{abstract}
In this study; the short films and videos taking part in National Instructional Short Film and Video Contest held in Kurikkale University are evaluated in terms of some variables such as; the departments of the teacher candidates, whether the product is video or film. Quantitative methods were used in the study. The research method of the study is descriptive method. Quantitative data was obtained by using Short Movie and Video Assessment Scale prepared by the researchers the rubric consists of four sub-titles, the usage of audio-visual elements, focusing the aims and objectives, selection and presentation of the content, taking target group into consideration. There are 20 items in the scale. Each item can be graded between 1-10 and the arithmetic mean of the items gives the total point of the films. All of the 47 films taking part in the contest were evaluated. According to the results, these films and videos are graded as average. Besides this, there are no significant difference between instructional short film and videos in terms of technical aspects, content, aims and objectives; but for the target group/audience, videos are graded as more effective than short films. In addition, the scores of the instructional short films and videos prepared by the students in Department of Computer and Instructional Technologies are considerably higher than the other departments' scores.
\end{abstract}

Keywords: Instructional Short film, instructional video, social media, internet and education

\section{Extended Abstract}

Purpose and Significance: Social media is a system in which users can share information synchronous and conduct discussions without time or place limitation. On social media platforms, people can ask for help or help others. In addition, all kinds of writing, ideas, images, video sharing can be done by using social media. In this aspect, Social can be used as a means of informal education (http://tr.wikipedia.org/wiki/Sosyal_medya). Instructional short movies and videos are tools offering students indirect experiences and enhancing the teaching-learning process (Bruner, 2008). In addition, Instructional short movies and videos which can be used to provide permanent and effective learning, support the learning and developmental structure of the brain. In this context the aim of the study is to evaluate the short films and videos taking part in National Instructional Short Film and Video Contest held in Kirikkale University in terms of some variables such as; the departments of the teacher

\footnotetext{
* This article was presented at the 22. National Educational Sciences Congress, 5-7 September 2013, Osmangazi University, Eskişehir, Turkey.

** Corresponding Author: Assoc. Prof. Dr., Kırıkkale University, Kırıkkale, Turkey, oktayakbas@ hotmail.com

*** Research Assistant, Kırıkkale University, Kırıkkale, Turkey, serap_canoglu@hotmail.com

**** Research Assistant, Kırıkkale University, Kırıkkale, Turkey, metuceylan@gmail.com
} 
candidates, whether the product is video or film and to some suggestions related to the usage of short movies and videos in instructional settings.

Methods: Quantitative methods were used in the study. The research method of the study is descriptive method. Quantitative data was obtained by using Short Movie and Video Assessment Scale prepared by the researchers the rubric consists of four subtitles, the usage of audio-visual elements, focusing the aims and objectives, selection and presentation of the content, taking target group into consideration. There are 20 items in the scale. Each item can be graded between $1-10$ and the arithmetic mean of the items gives the total point of the films. All of the 47 films taking part in the contest were evaluated.

Results: According to the results, these films and videos are graded as average. In the evaluation of all of the instructional short movies and videos participating in the competition according to the scores obtained from the sub titles of the scale, their points seem to be quite close to each other. Therefore it can be said that all of the four subtitles - the usage of audio-visual elements, focusing the aims and objectives, selection and presentation of the content, taking target group into consideration - are inter-related. There are no significant difference between instructional short film and videos in terms of technical aspects, content, aims and objectives; but for the target group/audience, videos are graded as more effective than short films. In addition, the scores of the instructional short films and videos prepared by the students in Department of Computer and Instructional Technologies are considerably higher than the other departments' scores.

Discussion and Conclusions: Integration of the advanced cameras, into mobile phones and computers makes film and video shooting easier with much less cost. Internet and Social media user not only watch films but also try to produce more creative and innovative efforts for information sharing. People using websites such as "YoutubeEducation", "Coursera", "khanacademy", "Vitamin Egitim", for educational purposes give important clues for the future of short movies and videos usage in settings. All of these developments show that instructional short movies and videos contributed and will continue contributing to lifelong and individual learning. 


\title{
Eğitsel Kısa Film ve Videoları Yeniden Düşünmek: Eğitsel Kısa Film ve Video Yarışmasına İlişkin Bir Değerlendirme*
}

\author{
Oktay AKBAŞ ${ }^{* *}$ \\ Serap Nur CANOĞLU ${ }^{* * *}$ \\ Mustafa CEYLAN ${ }^{* * * *}$
}

Makale Gönderme Tarihi: 31 Ocak 2014

Makale Kabul Tarihi: 01 Mart 2015

ÖZET: Bu çalışmada ulusal eğitsel kısa film ve video yarışmasına katılan eserler, öğretmen adaylarının öğrenim gördükleri bölüm, eserlerin film ya da video özelliği taşıma durumu gibi değişkenler bağlamında değerlendirilmiştir. Araştırmada betimsel yöntem kullanılmıştır. Araştırmacılar tarafindan geliştirilen eğitsel kısa film ve video değerlendirme ölçeği ile nicel veriler elde edilmiştir. Geliştirilen değerlendirme ölçeği; görsel ve işitsel öğelerin kullanımı, hedefe odaklanma, içerik seçimi ve sunumu ile hedef kitleyi dikkate alma olarak dört başlık halinde yirmi madde olarak hazırlanmış ve her bir maddeye 1 ile 10 arasında verilen puanların aritmetik ortalaması alınarak kısa film ve videonun başarı puanı belirlenmiştir. Yarışmaya katılan 47 eserin tamamı değerlendirmeye alınmıştır. Yapılan değerlendirme, eğitsel film ve videolar arasında görsel ve işitsel ögelerin kullanımı, hedefe odaklanma, içerik seçimi ve sunumu alt boyutlarında anlamlı düzeyde fark olmadığını, hedef kitleyi dikkate alma alt boyutunda ise eğitsel videoların daha etkili olduğunu göstermiştir. Ayrıca Bilgisayar ve Öğretim Teknolojisi bölümü öğrencileri tarafından hazırlanan film ve videoların değerlendirme puanlarının anlamlı olarak daha yüksek olduğu bulunmuştur.

Anahtar Kelimeler: Eğitsel Kısa Film, Eğitsel Video, Sosyal Medya İnternet ve Eğitim

\section{Giriş}

Sosyal medya zaman ve mekân sınırlaması olmadan, paylaşımın, tartı̧̧manın esas olduğu, çift taraflı ve eş zamanlı bilgi paylaşımını sağlayan medya sistemidir. Sosyal medya platformlarında insanlara yardım etme, yardım alma, her türlü yazı, fikir, görsel, video paylaşımı yapılabilmektedir. Bir yönüyle sosyal medya resmi olmayan eğitim yollarından da bir tanesidir (http://tr.wikipedia.org/wiki/Sosyal_medya). 2013 yılı itibariyle 1 milyar kişinin bir sosyal ağ uygulaması olan Facebook kullanıcısı olduğu belirtilmektedir (http://en.wikipedia.org/wiki/Facebook). Bir dakikada YouTube video paylaşım platformuna 10 saatlik video yüklenmektedir. Resim barındırma sitesi Flickr'da 3 milyar fotoğraf yüklenmiş durumdadır. ForresterResearch'a göre, kullanıcılar sadece pasif izleyici değil aynı zamanda bloglara, okuma ya da alışveriş sitelerine yorumlarıyla katkıda bulunmaktadır.

\section{Sosyal Medya Ortamları ve Video}

Facebook'un kullanıcıların 18-30 yaş grubu aralığında daha yoğun olduğu ortaya çımıştır (Şener, 2010). Facebook'u kullanma amaçlarının en önemlileri olarak ilk sırada arkadaşlarıyla iletişim kurmak (\%66.2), izini kaybettiği arkadaşlarını/tanıdıklarını bulmak (\%37.7) ve hoşuna giden videoları/fotoları paylaşmak (\%20.6) olduğu belirtilmektedir. Video izlemek en sık yapılan üçüncü etkinliği oluşturmaktadır. Kullanıcılar video paylaşmaktan çok video izlemeyi tercih etmektedirler. Kullanıcıların

\footnotetext{
* Bu makale, 5-7 Eylül 2013 tarihlerinde Eskişehir'de Osmangazi Üniversitesi tarafindan düzenlenen 22.Ulusal Eğitim Bilimleri Kurultayı'nda sözlü bildiri olarak sunulmuştur.

*** Sorumlu Yazar: Doç. Dr., Kırıkkale Üniversitesi, Kırıkkale, oktayakbas@ hotmail.com

**** Arş.Gör., Kırıkkale Üniversitesi, Kırıkkale, serap_canoglu@hotmail.com

**** Arş.Gör., Kırıkkale Üniversitesi, Kırıkkale, metuceylan@gmail.com
} 
yarıdan çoğu çok sık ve sık sık video izlediklerini belirtirken, video paylaşanların oranı tüm kullanıcıların üçte birini geçmemektedir (Şener, 2010). Aynı şekilde TTNET tarafından açıklanan internet kullanım verilerine göre, Türkiye'deki internet trafiğgini en çok meşgul eden eylemin video izlemek olduğu açıklanmıştır. Türkiye'de Youtube hariç video sitelerinde video izlemek internet trafiğinin \% 28,97'sini oluştururken, YouTube ise tek başına bu trafiğin \% 8,47'sini yaratmaktadır (http://blog.ttnet.com.tr/). Video paylaşım siteleri ağırlıklı olarak müzik ve eğlence için kullanılsa da yeni bilgileri öğrencilere aktarmak amaciyla bir pedagojik bir kaynak olarak kullanılmaya da başlanmıştır (Duffy, 2009).

\section{Bir Eğitim Aracı Olarak Kısa Film ve Video}

Eğitsel filmler ve videolar, öğrencilere dolaylı deneyimler sunan ve öğrenmeöğretme sürecini zenginleştiren araçlardır (Bruner, 2008). Aynı zamanda formal ve informal eğitimde öğrenmeyi daha eğlenceli hale getirmek, kalıcı ve etkili öğrenmeyi sağlamak için kullanılabilecek çok iyi bir eğitim aracı olan kısa filmler ve videolar, beynin öğrenme ve gelişim yapısını da destekler niteliktedir. Bir video klip beynin her iki lobunu da meşgul etmektedir. Beynin sol tarafı diyalog, tema, ritim ve sözlü ifadelerle işlem yaparken; sağ tarafı görsel imgeler, ilişkiler, ses, melodi ve uyumlu ilişkilerle işlem yapmaktadır (Hébert \& Peretz, 1997).

Eğitsel film ve videoların eğitim amacıyla kullanımı ve faydalarına yönelik yurt içinde ve yurt dışında birçok yeni çalışma yapılmıştır. Yurt dışında yapılan bir çalışmada öğrencilere derse geçmeden önce şekerin üretim sürecini anlatan kısa film gösterilmiştir. Çalışmada eğitsel filmlerin karmaşık konulara geçmeden önce "ön örgütleyici” olarak kullanılabileceği sonucuna varılmıştır (Michel, Roebers ve Schneider, 2007). Bir başka çalışmada beyin tümörü hastalarında aile bakıcılığının önemi konusunda çekilmiş ödüllü bir belgesel film beyin cerrahları, nörologlar, hasta bakıcıları ve diğer sağlı eğitimcilerine izletilmiştir. Filmi izleyen grubun neredeyse tamamı filmin aile bakıcılığı konusunda faydalı ve etkili olduğu yönünde görüş belirtmiştir (Rabow, Goodman, Chang, Berger ve Folkman, 2010). Barnett, Wagner, Gatling, Anderson, Houle ve Kafka (2006) tarafından yapılan araştırmada da popüler bilim kurgu filmleri öğrencilerin bilimsel kavramları anlamlandırmasında ve zihinsel yapılarının oluşmasında etkili bulunmuştur. Prensky (2000) tarafından yapılan bir diğer araştırmada, videoların sabırsız öğrenenler için dikkati toplayabilen multimedya elemanlara sahip olması nedeniyle tercih edildiği belirtilmiştir. İyi bir videonun en önemli elemanının yüksek kaliteli görsel içeriğe sahip olmak ve hızlı indirilebilmek olduğu ifade edilmiştir.Çalışmayla ilgili olarak Clark ve Mayer (2003)' in fazlalık prensibine göre de, gereksiz ses öğrenme için zararlıdır. Bu çalışma sonucunda öğrenci görüşlerinden elde edilen bir diğer bulgu da, iyi bir videoda başlıkların olması gerektiğidir. Başlıkları ve altyazısı bulunan videoların özellikle dil yeterliliğinde eksikleri olan öğrenenler için avantaj olduğunu görülmüştür.

$\mathrm{Bu}$ noktada video destekli yapılandırmacı anlayışa dayanan çağdaş bir öğretim metodu olan flipped classroom fikri ön plana çıkmaktadır. "Flipped Classroom" fikri Khan Academy'nin kurucusu Salman Khan'nın çalışmaları ile popülerleşmiş ve 
teknolojiye meraklı pek çok eğitimcinin dağarcığına yerleşmiştir. Bu metodun temel varsayımı öğrenciler sınıfa girmeden önce derste işlenecek konuyu eğitsel videolar üzerinden öğrenmesi ve öğretmenler derslerde içeriği destekleyici etkinliklere daha fazla zaman ayırabilecekler olmasıdır (Tucker, 2012). Flipped Classroom metodunu kullanmanın arkasındaki temel fikir öğrenci-merkezli ve grup çalışmalarına, araştırmaya, yaratıcılığa, problem çözmeye yönelik aktivitelerin yer aldığı bir öğrenme ortamı yaratmak, sınıfları bir laboratuara, bir stüdyoya çevirmek öğretmeni bilgi yayan araç rolünden kurtarmak, öğrenciyi sadece bilgiyi emen değil, işleyen ve oluşturan bireylere dönüştürmek, kısaca "yapılandırmacı” bir soluk getirmektir (Aybat, 2013).

Bir eğitim aracı olarak film ve videolar öğretmen eğitiminde de kullanılmaktadır. Son yıllarda yapılan çalışmalardan birinde öğretmen adaylarının sınıf yönetimiyle ilgili videolar geliştirmeleri ve analiz etmeleri istenmiştir. Bu faaliyetlerin öğretmen adaylarının öğrenme aktiviteleri ile ilgili olumlu çıkarımlarda bulunmalarını sağladığı ve öğretmen adaylarının derste tecrübe ettikleri ile gelecekte tecrübe edecekleri şeyleri anlamlandırmasını sağladığı belirtilmiştir (Koç, 2011). Beck ve Kasnik de böyle bir sürecin yapılandırmacı olduğunu; çünkü bu yöntemin eski kavramlara bağlı olarak yeni kavramların oluşturulmasını sağladığını, bilgi ve hayat arasında bağlantı kurduğunu ve nasıl öğreteceğini öğrenmeye yönelik ilk deneyimlere katkı sağladığını ifade etmiştir (akt. Koç, 2011). Ayrıca çalışma sonuçlarına göre, stajyer öğretmenler bu çalışma ile empati çalışmaları yapmış mesleğini keşfetmiştir. Bu yöntemin, akranlarla video paylaşımını, içeriğin sunumunu ve çoklu bakış açısının önemine yönelik yapıcı düşünce geliştirmesini sağlaması çalışmanın diğer önemli bulgularındandır. Buna yönelik Jonassen (1999) de, öğrenenlerin farklı bakış açılarına ve örneklere maruz kalmasının, gerçek uygulamaları değerlendirme ve bunlarla ilgili konuşma fırsatı sağladığını belirtmiştir. Başka bir çalışmada da öğretmen adayları tarafından hazırlanan eğitsel kısa filmler için, uygulamalı olarak anlatma, nasıl sorusuna cevap verme, fikir edinmeyi ve farkındalığı sağlama gibi faydalar ifade edilmiştir (Akbaş, 2011).

\section{Film ve Video Arasındaki Temel Farklar}

Video ile sinema arasındaki farklardan birisi; videonun, sinemanın dayandığı birçok temele dayanmaması; oyuncu, diyalog, konu, senaryo gibi öğelere sahip olmak zorunda olmamasıdır (Rush, 1999). Yani kısa filmden farklı olarak aniden gelişen bir kurgu söz konusudur. Üreticinin kafasında ortaya çıkaracağı video ile ilgili bir akış planı olmuş olsa da video çekimi sırasında gelişen olaylar, tepkiler, konuşmalar, hareketler, videoya sonradan dâhil olan kişiler vs. konuyu farklı bir şekilde şekillendirebilir (Ergin, 2011).Videoların filme göre daha serbest olduğu ve olayların spontane gelişmesine imkan tanıdığı, izleyicide sinema nedeniyle oluşmuş klişelere saldırıda bulunduğu söylenebilir (Rush, 1999). Film ve videonun diğer bir farkı ise videonun filme göre daha özgür olması ve kurulan ilişskinin daha yakın ve birebir algilanmasidir (Y1lmaz, 2012).

Günümüzde hem film hem de video çekimi ve paylaşımının kolaylaşmış, pasif izleyici konumundaki birçok insan üretici ve paylaşıcı durumuna geçmiştir. Öğretmen 
adayları tarafından hazırlanan film ve videolar ile öğrenme aktiviteleri planlama, uygulama, kendi deneyimleri hakkında yansıtıcı düşünme ve öğrenme sürecini anlamlandırma gibi birçok olumlu davranış beklenmektedir. Çalışmada diğer bir önemi ise internette eğitsel içeriğin artırılmasına katkı sağlamaktır. Bu bulgular doğrultusunda öğretmen adaylarının yarışmacı olduğu eğitsel kısa film ve video yarışması düzenlenmiş, dereceye giren eserler internet ve sosyal medya üzerinden paylaşılmış ve bu çalışma ile değerlendirilmiştir. Bu açıklamalar doğrultusunda çalışmanın amacı ve alt amaçları aşağıda verilmiştir.

\section{Amaç ve Alt Amaçlar}

Bu çalışmada, 9 Mayıs 2013 tarihinde Kırıkkale Üniversitesi Eğitim Fakültesi'nde yapılan Ulusal Eğitsel Kısa Film ve Video Yarışması'na katılan eserler öğretmen adaylarının öğrenim gördükleri bölüm, eserlerin film ya da video özelliği taşıma durumu gibi değişkenler bağlamında değerlendirilmesi yapılmıştır ve öneriler geliştirilmiştir.

1. Ulusal Eğitsel Kısa Film ve Video Yarışmasına katılan ve dereceye giren eserlerin puanları nasıldır?

2. Yarışmaya katılan film ya da videoların puanları arasında anlamlı düzeyde fark var midir?

3. Yarışmaya katılan öğretmen adaylarının bölümlerine göre hazırladıkları film ve videoların aldıkları puanlar arasında fark var mıdır?

\section{Yöntem}

$\mathrm{Bu}$ bölümde araştırmanın modeli, örneklem-çalışma gurubu, veri toplama araçları, verilerin toplanması ve verilerin çözümlenmesi ile ilgili bilgiler verilmiştir. Bu çalışmada betimsel araştırma yönteminden yararlanılmıştır. Betimsel çalışma, çok sayıda elemandan oluşan bir evrende, evren hakkında genel bir yargıya varmak amacı ile evrenin tümü ya da ondan alınacak bir grup üzerinde yapılan tarama düzenlemeleridir (Karasar, 2004). Betimsel çalışmalar olayların, objelerin ve diğer farklı alanların betimlenmeye, açıklanmaya çalışıldığı durumlarda kullanılır (Üstün ve Bozkurt, 2003).

\section{Evren ve Örneklem}

Türkiye'nin on farklı üniversitesinden 47 farklı film ve videoyu inceleyen 20 uzman, çalışmanın örneklemini oluşturmuştur. Bu uzmanlar, öğretim elemanlarından, geçmiş yıllarda film ve video hazırlamış lisans ve yüksek lisans öğrencilerinden oluşmaktadır. Uzmanların unvan, bölüm ve cinsiyetlerine göre dağılımı Tablo 1'de verilmiştir. 


\section{Tablo 1}

Incelenen Uzmanların Cinsiyet, Unvan ve Bölümlerine Göre Dă̆ılımı

\begin{tabular}{lc}
\hline Cinsiyet & Yüzde (\%) \\
\hline Kadın & 75 \\
Erkek & 25 \\
\hline Unvan & Yüzde (\%) \\
\hline Profesör & 5 \\
Doçent & 30 \\
Yrd. Doçent & 30 \\
Arş. Gör. & 20 \\
Öğrenci & 15 \\
\hline Bölüm & Yüzde (\%) \\
\hline Eğitim Bilimleri Bölümü & 25 \\
Fen Bilgisi Öğretmenliği & 25 \\
Sınıf Öğretmenliği & 25 \\
BÖTE & 15 \\
Türkçe Öğretmenliği & 10 \\
\hline
\end{tabular}

İncelenen film ve videoların üniversitelere göre dağılımı Tablo 2'de verilmiştir.

Tablo 2

Incelenen Film ve Videoların Üniversitelere Göre Dă̆ılımı

\begin{tabular}{lc}
\hline Üniversite & Kısa Film ve Video Sayısı \\
\hline Kırıkkale Üniversitesi & 21 \\
Karadeniz Teknik Üniversitesi & 6 \\
Orta Doğu Teknik Üniversitesi & 5 \\
Dokuz Eylül Üniversitesi & 5 \\
Balıkesir Üniversitesi & 4 \\
Ankara Üniversitesi & 2 \\
Sakarya Üniversitesi & 1 \\
Celal Bayar Üniversitesi & 1 \\
Ege Üniversitesi & 1 \\
İstanbul Üniversitesi & 1 \\
\hline Toplam & 47 \\
\hline
\end{tabular}


Yarışmaya katılan kısa film ve videoların öğretmen adaylarının öğrenim gördükleri bölümlere göre dağılımı ise Tablo 3'te verilmiştir.

Tablo 3

Incelenen Eserlerin Öğretmen Adaylarının Öğrenim Gördükleri Bölümlere Göre Dağılımı

\begin{tabular}{lc}
\hline Bölüm & Kısa Film ve Video Sayısı \\
\hline Bilgisayar ve Öğretim Teknolojileri Eğitimi Bölümü & 19 \\
Sınıf Öğretmenliği & 12 \\
Türkçe Öğretmenliği & 10 \\
Diğer & 6 \\
\hline Toplam & 47 \\
\hline
\end{tabular}

\section{Veri Toplama Aracı}

Eğitsel kısa film ve video değerlendirme ölçeği hazırlanması sürecinde ilk olarak bilimsel yayınlar taranmış ve bu yayınlarda bulunan benzer nitelikte ölçekler incelenmiştir. Ölçeğin geliştirilmesinde Eğitsel Video Değerlendirme Ölçeği (Morain and Swarts, 2012), Eğitsel Yazılım Değerlendirme Ölçeği (Ateş, 2010) ve Web Tabanlı Öğrenme Ortamları Değerlendirme Ölçeği (Baya'a, Mia'ari ve Baya'a, 2009) incelenerek madde havuzu oluşturulmuştur. Oluşturulan bu madde havuzuyla ilgili uzman görüşleri alınarak geliştirilen değerlendirme ölçeği; görsel ve işitsel ögelerin kullanımı, hedefe odaklanma, içerik seçimi ve sunumu ve hedef kitleyi dikkate alma olarak dört başlık halinde yirmi madde olarak hazırlanmıştır. Puanlama 1 (Etkisiz), 10 (Çok Etkili) şeklinde yapılmıştır.

\section{Verilerin Analizi}

Uzmanlar tarafından film ve videolar izlenmiş ve sonrasında eğitsel kısa film ve video değerlendirme ölçeği doldurulmuştur. Bir eser, en az 7, en fazla 13 kişi tarafından değerlendirilmiştir. Veriler üzerinde istatistiksel çözümlemeler için SPSS paket programından yararlanılmıştır. Verilerin yorumlanmasında öğrenci görüşlerinin frekans (f) ve yüzdeleri (\%), aritmetik ortalama ve standart sapma değerleri kullanılmıştır. Ayrıca değerlendirmeler arasındaki farkı belirlemek için t-testi ve varyans analizi yapılmıştır.

\section{Bulgular}

Ulusal eğitsel kısa film ve video yarışmasına katılan eserlerin genel değerlendirilmesi aşağıda verilmiştir. 
Tablo 4

Eğitsel Kısa Film ve Video Yarışmasında Dereceye Giren Eserler

\begin{tabular}{lccc}
\hline Filmin adı & Katılımcı & Üniversite & Ortalama puan \\
\hline $\begin{array}{l}\text { Ankara Tabiat Tarihi } \\
\text { Müzesi }\end{array}$ & Haluk Alp Çelik & ODTÜ Eğitim Fakültesi & 7.80 \\
\hline Hayatta Tasarruf & Uğur Aydın & $\begin{array}{c}\text { Balıkesir Üniversitesi, } \\
\text { Necatibey Eğitim Fakültesi }\end{array}$ & 7.53 \\
\hline İnsan ve Çevre & Alişan Çınar & $\begin{array}{c}\text { Kırıkkale Üniversitesi Eğitim } \\
\text { Fakültesi }\end{array}$ & 7.31 \\
\hline
\end{tabular}

Ulusal Eğitsel Kısa Film ve Video Yarışmasında birinciliği ODTÜ’nden Haluk Alp Çelik tarafından hazırlanan Ankara Tabiat Tarihi Müzesi isimli eser kazanmıştır. $\mathrm{Bu}$ eserin temel amacı, Ankara Tabiat Tarihi Müzesi'ni genel olarak tanıtmak ve müze kurallarını özellikle ilkokul ve ortaokul öğrencilerine yönelik olarak anlatmaktır. Eserin süresi, 5 dakika 41 saniyedir. Eserde müzik, kukla, görsellik, mizah dengeli bir şekilde amaç doğrultusunda kullanılmıştır. Yarışmada ikinci olan eser Uğur Aydın tarafından, üçüncü olan ise Alişan Çınar tarafindan hazırlanmıştır.

Ulusal Eğitsel Kısa Film ve Video Değerlendirme Ölçeği’ningörsel ve işitsel ögelerin kullanımı, hedefe odaklanma, içerik seçimi ve sunumu ile hedef kitleyi dikkate alma boyutlarına ilişkin veriler aşağıda verilmiştir.

Tablo 5

Yarışmaya Katılan Film ve Videoların Ölçeğin Alt Boyutlarına Göre Aldiğı Puanlar

\begin{tabular}{lccc}
\hline Ölçeğin Boyutları & $N$ & $\overline{\mathrm{x}}$ & ss \\
\hline Görsel ve işitsel ögelerin kullanımı & 395 & 6.15 & 1.39 \\
Hedefe odaklanma & 395 & 6.14 & 1.70 \\
İçerik seçimi ve sunumu & 395 & 6.15 & 1.59 \\
Hedef kitleyi dikkate alma & 394 & 6.15 & 1.65 \\
\hline
\end{tabular}

Yarışmaya katılan film ve videolar görsel ve işitsel ögelerin kullanımı, hedefe odaklanma, içerik seçimi ve sunumu ve hedef kitleyi dikkate alma alt boyutları dikkate alınarak değerlendirilmiştir. Öğretmen adayları tarafindan hazırlanan film ve videolar değerlendiriciler tarafından orta düzeyde etkili olarak değerlendirilmiştir. Alt boyutlara ilişkin puanlar incelendiğinde puanların birbirine oldukça yakın olduğu görülmektedir. $\mathrm{Bu}$ veriden hareketle ölçeğin alt boyutlarının birbirleriyle oldukça ilişkili olduğu söylenebilir. 
Resim 2. Ankara Tabiat Resim 3. İnternette Kötü

Resim 1. Yarışmanın afişi Tarihi Müzesi Filminden Bir Görüntü Örnek Mehmet Can İsimli Filmden Bir Görüntü
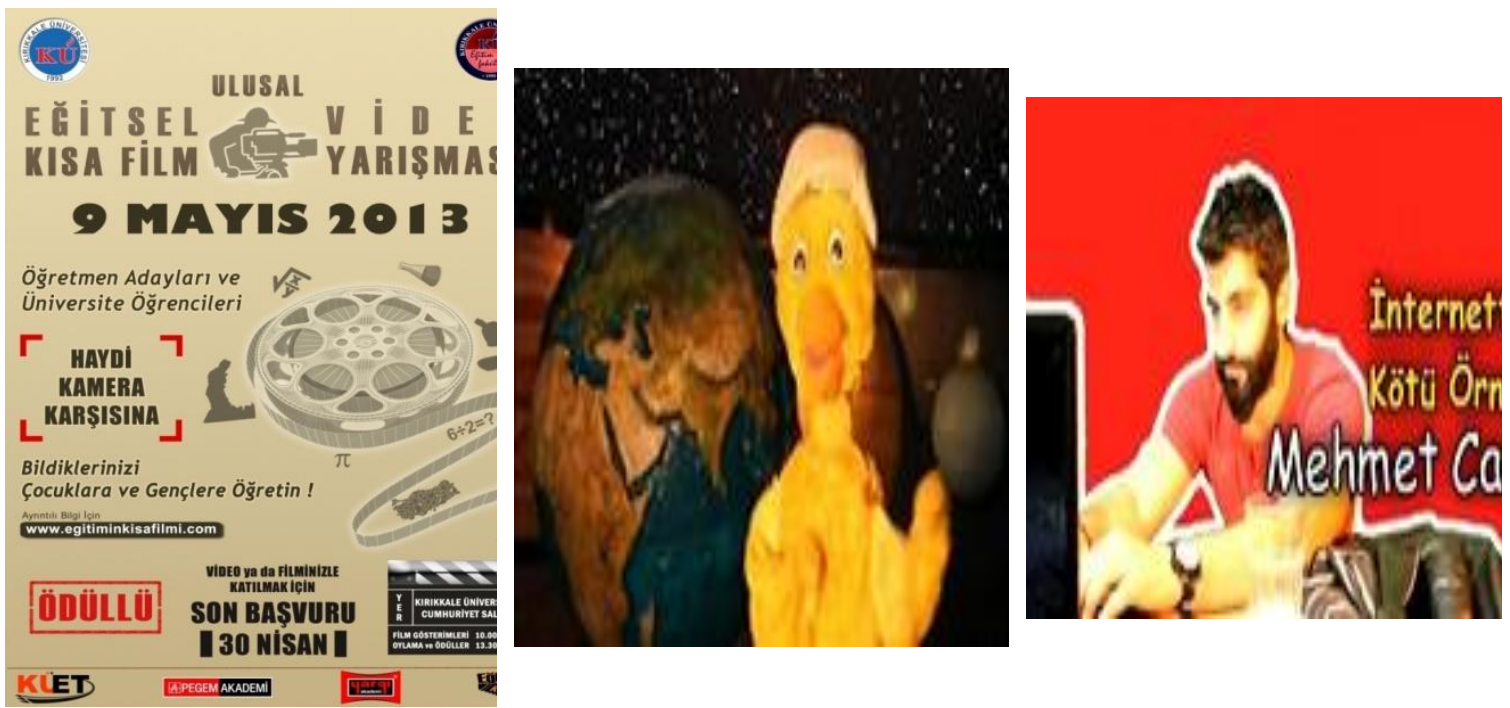

Aşağıda yarışmaya katılan film ya da videoların puanları arasında anlamlı düzeyde fark olup olmadığı test edilmiş ve tablolaştırılmıştır.

Tablo 6

Film ve Videolar Arasındaki Puan Farkının Değerlendirilmesi

\begin{tabular}{|c|c|c|c|c|c|c|c|}
\hline Ölçeğin Boyutları & Türü & $N$ & $\overline{\mathrm{X}}$ & ss & $S d$ & $t$ & $p$ \\
\hline \multirow{2}{*}{$\begin{array}{l}\text { Görsel ve işitsel ögelerin } \\
\text { kullanımı }\end{array}$} & Film & 241 & 6.07 & 1.37 & \multirow[t]{2}{*}{3393} & \multirow[t]{2}{*}{-1.56} & \multirow[t]{2}{*}{.11} \\
\hline & Video & 154 & 6.29 & 1.37 & & & \\
\hline \multirow[t]{2}{*}{ Hedefe odaklanma } & Film & 241 & 6.10 & 2.10 & \multirow[t]{2}{*}{3393} & \multirow[t]{2}{*}{-1.16} & \multirow[t]{2}{*}{.2} \\
\hline & Video & 154 & 6.33 & 1.64 & & & \\
\hline \multirow[t]{2}{*}{ İçerik seçimi ve sunumu } & Film & 241 & 6.03 & 1.68 & \multirow[t]{2}{*}{3393} & \multirow[t]{2}{*}{-1.80} & \multirow[t]{2}{*}{.07} \\
\hline & Video & 154 & 6.33 & 1.43 & & & \\
\hline \multirow[t]{2}{*}{ Hedef kitleyi dikkate alma } & Film & 240 & 5.96 & 1.70 & \multirow[t]{2}{*}{3392} & \multirow[t]{2}{*}{-2.83} & \multirow[t]{2}{*}{.00} \\
\hline & Video & 154 & 6.44 & 1.53 & & & \\
\hline
\end{tabular}

Yarışmaya katılan eğitsel kısa filmlerin "görsel ve işitsel ögelerin kullanımı" puanı ortalamas1 $(\overline{\mathrm{x}}=6.07)$, videoların ise $(\overline{\mathrm{x}}=6.29)$ 'dur. Ortalamalar arasındaki farklılığı tespit etmek amacıyla yapılan $\mathrm{t}$-testi anlamlı çıkmamıştır $\left(\mathrm{t}_{(393)}=-1.56, p>.05\right)$. 
Yarışmaya katılan eğitsel kısa film ve videoların görsel ve işitsel ögelerin kullanımı boyutunda anlamlı düzeyde fark olmadığı görülmektedir. Buna göre eserlerin, film veya video olması görsel ve işitsel ögelerin kullanımı boyut üzerinde etkili değildir.

Yarışmada yer alan eğitsel kısa filmlerin ve videoların "hedefe odaklanma" boyutuna ilişkin puan ortalamaları sırasıyla $(\overline{\mathrm{x}}=6.10)$ ile $(\overline{\mathrm{x}}=6.33)$ 'dür. Her iki ortalama arasında farklılığı ortaya koymak amacıyla yapılan t-testi anlamlı çıkmamıştır $\left(\mathrm{t}_{(393)}=-1.16, p>.05\right)$. Yarışma dahilindeki eğitsel kısa filmlerin "içerik seçimi ve sunumu" başlığına ilişkin puan ortalaması $(\bar{x}=6.03)$ iken, videoların puan ortalaması $(\overline{\mathrm{x}}=6.33)$ 'dür. Ortalamalar arasındaki farklılı̆̆ 1 belirlemek amaciyla yapılan t-testi anlamlı değildir $\left(\mathrm{t}_{(393)}=-1.80, p>.05\right)$.

Yarışmada yer alan eğitsel kısa film ve videoların "hedef kitleyi dikkate alma" boyutuyla ortaya çıkan puan ortalamaları sırasıyla $(\bar{x}=5.96)$ ve $(\bar{x}=6.44)$ olmuştur. Her iki ortalama arasındaki farklılığı ortaya koymak amacıyla yapılan t-testi anlamlı çıkmıştır $\left(\mathrm{t}_{(392)}=-2.83, p<.05\right)$. Hazırlanan videoların filmlere göre hedef kitleyi dikkate alma boyutunda daha başarılı oldukları görülmüştür. Buna göre; hazırlanan eğitsel videoların, filmlere göre hedef kitleyi daha çok dikkate alarak hazırlandığı söylenebilir.

Tablo 7

Film ve Videolar Arasındaki Puan Farkının Adayların Bölümlerine Göre Değerlendirilmesi

\begin{tabular}{llccccc}
\hline & & $\begin{array}{c}\text { Kareler } \\
\text { Toplamı }\end{array}$ & $d f$ & $\begin{array}{c}\text { Kareler } \\
\text { Ortalaması }\end{array}$ & $F$ & $p$ \\
\hline Görsel ve işitsel & Grup Arası & 53.985 & 3 & 17.995 & 10.138 & .000 \\
ögelerin kullanımı & Grup İçi & 694.005 & 391 & 1.775 & & \\
& Toplam & 747.990 & 394 & & & \\
\hline \multirow{2}{*}{ Hedefe odaklanma } & Grup Arası & 48.667 & 3 & 16.222 & 4.415 & .005 \\
& Grup İçi & 1436.710 & 391 & 3.674 & & \\
& Toplam & 1485.377 & 394 & & & \\
\hline \multirow{2}{*}{$\begin{array}{l}\text { İcrik seçimi ve } \\
\text { sunumu }\end{array}$} & Grup Arası & 69.400 & 3 & 23.133 & 9.703 & .000 \\
& Grup İçi & 932.177 & 391 & 2.384 & & \\
\hline \multirow{2}{*}{ Hedef kitleyi dikkate } \\
alma & Toplam & 1001.577 & 394 & & & \\
& Grup Arası İçi & 73.439 & 3 & 24.480 & 9.517 & .000 \\
& Toplam & 1003.169 & 390 & 2.572 & & \\
\hline
\end{tabular}

Tablo 7 incelendiğinde, yarışmada yer alan kısa film ve videoların puanlarının, yarışmaya katılan öğrencilerin bölümleri açısından "görsel ve işitsel ögelerin kullanımı" boyutta anlamlı şekilde farklılaştığ görülmektedir $\left(\mathrm{F}_{(3-391)}=10.13 ; p<.05\right)$. Aynı şekilde 
"hedefe odaklanma" boyutunda $\left(\mathrm{F}_{(3-391)}=4.41 ; p<.05\right)$, "içerik seçimi ve sunumu" boyutunda $\left(\mathrm{F}_{(3-391)}=9.70 ; \quad p<.05\right)$ ve "hedef kitleyi dikkate alma" boyutunda $\left(\mathrm{F}_{(3-390)}=9.51 ; p<.05\right)$ yarışmaya katılan öğrencilerin bölümlerinin, yarışmada yer alan eserlerin puan ortalamalarını etkilediği görülmüştür. Buna göre, yapılan scheffe testi sonuçları Bilgisayar ve Öğretim Teknolojileri Eğitimi bölümü öğrencilerinin, yarışmaya katılan diğer bölümlerin öğrencilerine (Sınıf Öğretmenliği, Türkçe Öğretmenliği ve diğer) göre görsel ve işitsel ögelerin kullanımı, hedefe odaklanma, içerik seçimi ve sunumu ve hedef kitleyi dikkate alma boyutlarında daha başarılı oldukları anlaşılmıştır.

\section{Sonuç ve Tartışma}

$\mathrm{Bu}$ çalışmada ulusal eğitsel kısa film ve video yarışmasına katılan eserlerin genel değerlendirmelerine ek olarak; öğretmen adaylarının öğrenim gördükleri bölüm, eserlerin film ya da video özelliği taşıma durumu gibi değişkenler bağlamında değerlendirilmesi yapılmıştır. Birinci alt amaca yönelik olarak yapılan analizde, yarışmaya katılan film ve videoların orta düzeyde etkili olarak değerlendirildiği görülmüştür. Yarışmada birinci olan videoda Ankara Tabiat Tarihi Müzesi genel olarak tanıtılmakta ve müze kuralları özellikle ilkokul ve ortaokul öğrencilerine yönelik olarak anlatılmaktadır. Eserde müzik, kukla, görsellik, mizah dengeli bir şekilde amaç doğrultusunda kullanılmıştır. Ayrıca yine bu videoda eğlence, eğitsel yön, ses, görüntü, zaman kullanımı tam bir bütünlük içerisindedir. $\mathrm{Bu}$ eseri; belirli bir kazanımdoğrultusunda hazırlanmış olması, bu kazanımın gerektirdiği davranışları öğrenciye etkili bir şekilde aktaracak görsel ve yazılı öğeler içermesi ve bu öğelerin hedef kitleyi dikkate alması özellikleri ön plana çıkarmıştır. Yarışmaya katılan tüm film ve videoların, değerlendirme ölçeğinin alt boyutlarından aldıkları puanlara göre yapılan değerlendirmede puanların birbirine oldukça yakın olduğu görülmektedir. $\mathrm{Bu}$ veriden hareketle görsel ve işitsel ögelerin kullanımı, hedefe odaklanma, içerik seçimi ve sunumu ve hedef kitleyi dikkate alma alt boyutlarının birbirleriyle oldukça ilişkili olduğu söylenebilir.

İkinci alt amaca yönelik elde edilen bulgularda, video ve filmlerin değerlendirme puanlarının anlamlı düzeyde farklılığa sahip olup olmadığı yapılan t-testi ile belirlenmiştir. Elde edilen bu bulgularda görsel ve işitsel ögelerin kullanımı, hedefe odaklanma ve içerik seçimi ve sunumu alt boyutlarında kısa film ve video arasında anlamlı bir farklılık olmadığı görülürken, hedef kitleyi dikkate alma alt boyutunda eğitsel videolar lehine anlamlı bir farklılık bulunmuştur. $\mathrm{Bu}$ farklılık, videoda kendiliğinden ya da spontane gelişen bir kurgunun söz konusu olması (Rush, 1999), video çekimi sırasında gelişen olaylar, tepkiler, konuşmalar ve hareketlerin içtenliği artırması (Ergin, 2011) gibi özellikleri nedeniyle oluşmuş olabilir. Ayrıca video görüntüleriyle kurulan ilişki bir ölçüde daha yakın ve birebir algılanmış olabilir (Y1lmaz, 2012). Araştırmada, üçüncü alt amaca yönelik elde edilen bulgularda ise, eserleri hazırlayan öğrencilerin bölümleri ile kısa filmlerin ve videoların etkililiği arasında anlamlı bir fark olduğu yapılan varyans analizi ile belirlenmiştir. Buna göre; görsel ve işitsel ögelerin kullanımı, hedefe odaklanma, içerik seçimi ve sunumu ve 
hedef kitleyi dikkate alma alt boyutlarında Bilgisayar ve Öğretim Teknolojileri Eğitimi bölümü öğrencilerinin diğer bölümlere göre daha başarılı olduğu anlaşılmıştır.

\section{Öneriler}

Gelişmiş kameraların cep telefonuna ve bilgisayarlara entegre edilmesi ile çok az maliyetle film ve video çekimi ve montajı kolaylaşmıştır. İnternet ve sosyal medya kullanıcıları ise, sadece film ve video izlemekle yetinmemekte, aynı zamanda bilginin paylaşımı ile ilgili daha yaratıcı ve daha yenilikçi çalışmalar ortaya koymaktadır. Youtube-Education, Coursera, khanacademy, vitaminegitim gibi birçok sitede internetten dersler verilmesi, ders anlatımı videolarına ulaşılabilmesi ve yüz binlerce insanın bu sitelerden faydalanması bu sürecin geleceği hakkında önemli ipuçları vermektedir. 2000 yılında Massachusetts Teknoloji Enstitüsü’nün (MIT) öncülüğünde başlatılan Açık Ders Malzemeleri girişiminin amacı da yükseköğrenim kurumlarında verilen derslerin internet üzerinden açık kullanıma sunulmasını sağlamaktır. Bireysel ve kurumsal olarak ortaya çıkan bu gelişmeler, eğitim amaçlı videoların yaşam boyu öğrenmeye, bireysel öğrenme sürecine katkılar sağladığı ve sağlayacağını göstermektedir. Eğitsel film ve videolar bilgi paylaşımı teşvik etmesinin yanında, nasıl öğretebilirim?, dikkatleri nasıl çekmeliyim?, öğrenci olsam bu benim dikkatimi çeker mi?, bu konuyu yeniden öğretsem aynı yolu kullanır mıyım? Gibi sorularla öğrenme ve öğretme becerilerinin gelişimine de katkı sağladığı anlaşılmaktadır. 


\section{Kaynakça}

Akbaş, O. (2011). Bir Öğrenme Nesnesi Olarak Eğitsel Kısa Filmler: Öğretmen Adaylarının Çektikleri Eğitsel Kısa Filmler Üzerine Bir Değerlendirme. Gazi Üniversitesi Endüstriyel Sanatlar Eğitim Fakültesi Dergisi, 27, 15-27.

Ateş, A. (2010).Eğitsel yazılım değerlendirme ölçeği: geçerlik ve güvenirlik çalışması. Bu çalışmanın bir bölümü, 26-28 Nisan tarihleri arasında Boğaziçi Üniversitesi'nde düzenlenen International Educational Technology Conference (IETC) 2010'da sözlü bildiri olarak sunulmuştur.

Aybat, B (2013). Sinıfinızl Ters Yüz Edin. $0308 \quad 2013$ tarihinde http://www.burcuaybat.com/ sinifinizi-ters-yuz-edin/ internet adresinden alınmıştır.

Barnett, M.,Wagner,H., Gatling, A., Anderson, J., Houle, M. ve Kafka A. (2006). “The impact of science fiction film on student understanding of science", Journal of Science Education and Technology, 15:2 179-190.

Baya'a, N., Mia'ari, H., Baya'a, A. (2009). A rubric for evaluating web-based learning environments. British Journal of Educational Technology,40:4, 761-763.

Bruner, J. (2008). Eğitim Süreci. (Çev. Talip Öztürk).Pegem Akademi. Ankara.

Duffy, P. (2009). Engaging the YouTube Google-Eyed Generation: Strategies for Using Web 2.0 in Teaching and Learning. Electronic Journal of e-Learning,:2:6, 119129.

Ergin, D. (2011). Görüntünün ötesinde, gerçeğin peşinde. 10.07.2013 tarihinde http://www.martidergisi.com/video-sanati-goruntunun-otesinde-gercegin-pesinde/ internet adresinden alınmıştır.

Hébert, S.,\&Peretz, I. (1997). Recognition of music in long-termmemory: Aremelodicand temporal patterns equal partners? Memory and Cognition, 25, 518533.

Jonassen, D. H. (1999). Designing constructivist learning environments. In C. M. Reigeluth (Ed.), Instructional-design theories and models: A new paradigm of instructional theory, Vol. II (pp. 215e239). Mahwah, NJ: Lawrence Erlbaum Associates.

Karasar, N. (2004). Bilimsel Araştırma Yöntemi, Ankara, 2004

Koç, M. (2011). Let's make a movie: Investigating pre-service teachers' reflections on using video-recorded role playing cases in Turkey. Teaching and Teacher Education. 27, 95-106.

Michel, E., Roebers, C., M., Schneider, W. (2007). "Educational films in the classroom: increasing the benefit", Learning and Instruction, 17:2, 172-183.

Morian, M.,Swarts, J. (2012). You Tutorial: a frame work for assessing in structional online video. Technical Communication Quarterly, 21:1, 6-24.

Rabow, M., W., Goodman, S., Chang, S., Berger, M., Folkman, S. (2010). "Filming the family: A documentary film to educate clinicians about family care givers of patients with brain tumors", Journal of Cancer Education, 25, 242-246. 
Rush, M. (1999), New Media in Late 20th-Century Art. Thames\& Hudson.

Chan, Y.M. (2010). Video instructions as support for beyond classroom learning. Procedia Socialand Behavioral Sciences, 9, 1313-1318.

Şener, G. (2010). Türkiye'de Facebook Kullanımı Araştırması. http://inet-tr.org.tr/ inetconf14/ bildiri/4.pdf sitesinden 31012013 tarihinde elde edilmiştir.

TTNET (2011). Türkiye'de Internet Kullanımıyla İlgili Carpıcı Veriler. 16072013 tarihinde $\quad$ http://blog.ttnet.com.tr/turkiye\%E2\%80\%99de-internet-kullanimiylailgili-carpici-veriler/internet adresinden alınmıştır.

Tucker, B. (2012). Online instruction at homefreesclass time forlearning. 17072013 tarihinde www.educationnext.org internet adresinden alınmıştır.

Üstün, A. , Bozkurt, E. (2003). İlköğretim Okulu Müdürlerinin Kendilerini Algılayışlarına Göre Problem Çözme Becerilerini Etkileyen Bazı Mesleki faktörler. Kastamonu Ĕ̆itim Dergisi, 11:2, 13-20.

$\begin{array}{llllll}\text { Wikipedia (2013). } & \text { Facebook. } & 26 & 07 & 2013 & \text { tarihinde }\end{array}$ http://en.wikipedia.org/wiki/Facebook internet adresinden alınmıştır.

Wikipedia (2013). Sosyal Medya.. $11 \quad 07 \quad 2013$ tarihinde http://tr.wikipedia.org/wiki/Sosyal_medya internet adresinden alınmıştır.

Y1lmaz, M. (2012). Film sanatları: canlandırma, sinema, video. 10.07.2013 tarihinde http://my.opera.com/mehmet\%20yilmaz/archive/monthly/?viewfull internet adresinden alınmıştır. 